\title{
Review \\ The Contribution of Autophagy and LncRNAs to MYC-Driven Gene Regulatory Networks in Cancers
}

\author{
Leila Jahangiri ${ }^{1,+}+\mathbb{D}$, Perla Pucci ${ }^{2,+}\left(\mathbb{D}\right.$, Tala Ishola ${ }^{1,+}{ }^{\text {, Ricky M. Trigg }}{ }^{3}$, John A. Williams ${ }^{4,5}$, Joao Pereira ${ }^{6}$, \\ Megan L. Cavanagh ${ }^{1}$, Suzanne D. Turner ${ }^{2,7}\left(\mathbb{D}\right.$, Georgios V. Gkoutos $4,5,8,9,10,11,12 \mathbb{D}$ and Loukia Tsaprouni ${ }^{1, *}$
}

1 Department of Life Sciences, Birmingham City University, Birmingham B15 3TN, UK; leila.jahangiri@bcu.ac.uk (L.J.); tala.ishola@bcu.ac.uk (T.I.); megan.cavanagh@mail.bcu.ac.uk (M.L.C.)

2 Division of Cellular and Molecular Pathology, Department of Pathology, University of Cambridge, Cambridge CB2 0QQ, UK; pp504@cam.ac.uk (P.P.); sdt36@cam.ac.uk (S.D.T.)

3 Department of Functional Genomics, GlaxoSmithKline, Stevenage SG1 2NY, UK; ricky.m.trigg@gsk.com

4 Institute of Translational Medicine, University Hospitals Birmingham NHS Foundation Trust, Birmingham B15 2TH, UK; j.a.williams@bham.ac.uk (J.A.W.); g.gkoutos@bham.ac.uk (G.V.G.)

5 Institute of Cancer and Genomic Sciences, College of Medical and Dental Sciences, University of Birmingham, Birmingham B15 2SY, UK

6 Department of Neurology, Massachusetts General Hospital, Harvard Medical School, Boston, MA 02114, USA; jdpereira@cantab.net

7 CEITEC, Masaryk University, 62500 Brno, Czech Republic

8 Mammalian Genetics Unit, Medical Research Council Harwell Institute, Oxfordshire OX11 ORD, UK

9 MRC Health Data Research, Birmingham B15 2TT, UK

10 NIHR Experimental Cancer Medicine Centre, Birmingham B15 2TT, UK

check for updates

Citation: Jahangiri, L.; Pucci, P.; Ishola, T.; Trigg, R.M.; Williams, J.A.; Pereira, J.; Cavanagh, M.L.; Turner, S.D.; Gkoutos, G.V.; Tsaprouni, L. The Contribution of Autophagy and LncRNAs to MYC-Driven Gene Regulatory Networks in Cancers. Int. J. Mol. Sci. 2021, 22, 8527. https:// doi.org/10.3390/ijms22168527

Academic Editor: Anindita Das

Received: 21 June 2021

Accepted: 5 August 2021

Published: 8 August 2021

Publisher's Note: MDPI stays neutral with regard to jurisdictional claims in published maps and institutional affiliations.

Copyright: (c) 2021 by the authors. Licensee MDPI, Basel, Switzerland. This article is an open access article distributed under the terms and conditions of the Creative Commons Attribution (CC BY) license (https:/ / creativecommons.org/licenses/by/ $4.0 /)$.
11 NIHR Surgical Reconstruction and Microbiology Research Centre, Birmingham B15 2TT, UK

12 NIHR Biomedical Research Centre, Birmingham B15 2TT, UK

* Correspondence: loukia.tsaprouni@bcu.ac.uk

+ These authors contributed equally to this study.

Abstract: MYC is a target of the Wnt signalling pathway and governs numerous cellular and developmental programmes hijacked in cancers. The amplification of MYC is a frequently occurring genetic alteration in cancer genomes, and this transcription factor is implicated in metabolic reprogramming, cell death, and angiogenesis in cancers. In this review, we analyse MYC gene networks in solid cancers. We investigate the interaction of MYC with long non-coding RNAs (lncRNAs). Furthermore, we investigate the role of MYC regulatory networks in inducing changes to cellular processes, including autophagy and mitophagy. Finally, we review the interaction and mutual regulation between MYC and lncRNAs, and autophagic processes and analyse these networks as unexplored areas of targeting and manipulation for therapeutic gain in MYC-driven malignancies.

Keywords: MYC; gene regulatory networks (GRNs); autophagy; lncRNAs

\section{Introduction to MYC Transcription Factors and Their Roles in Cancer}

The MYC family of proteins are basic helix-loop-helix leucine zipper (bHLHZip) transcription factors (TFs) under tight transcriptional regulation. The MYC family includes c-MYC (MYC), the first member identified in humans; MYCL; and MYCN [1], encoded by $c-M Y C, L-M Y C$, and N-MYC (MYCN) genes, respectively [2]. MYC TFs can be transactivated by forming heterodimers with their partner protein, MAX, which then bind to E-box motifs and, in association with the transcription machinery, trigger the regulation of proliferation, metabolism, differentiation, cell cycle, apoptosis, DNA damage, angiogenesis, protein synthesis, and mitochondrial function [3-5]. However, the low specificity of MYC binding to E-box motifs can lead to the activation of alternative pathways and changes to metabolic states [3-5]. Furthermore, MYC sits at the crossroads of numerous signalling pathways where it can act as an early response mediator, and precise regulation of MYC expression is critical for maintaining the balance between proliferative and differentiated 
cellular states [6]. MYC TFs are downstream of the Wnt signalling pathway and can be aberrantly expressed due to mutations in $\beta$-catenin and APC and modulation by non-coding RNAs $[7,8]$. MYC expression is also dependent on other signalling pathways, including $\mathrm{PI}$ IK/AKT/mTOR, Notch, TGF- $\beta$ /SMADs, and growth factor-induced pathways [9-11]. In Figure 1, we highlighted the roles of Wnt, EGF, and TGF- $\beta$ signalling pathways in MYC regulation.

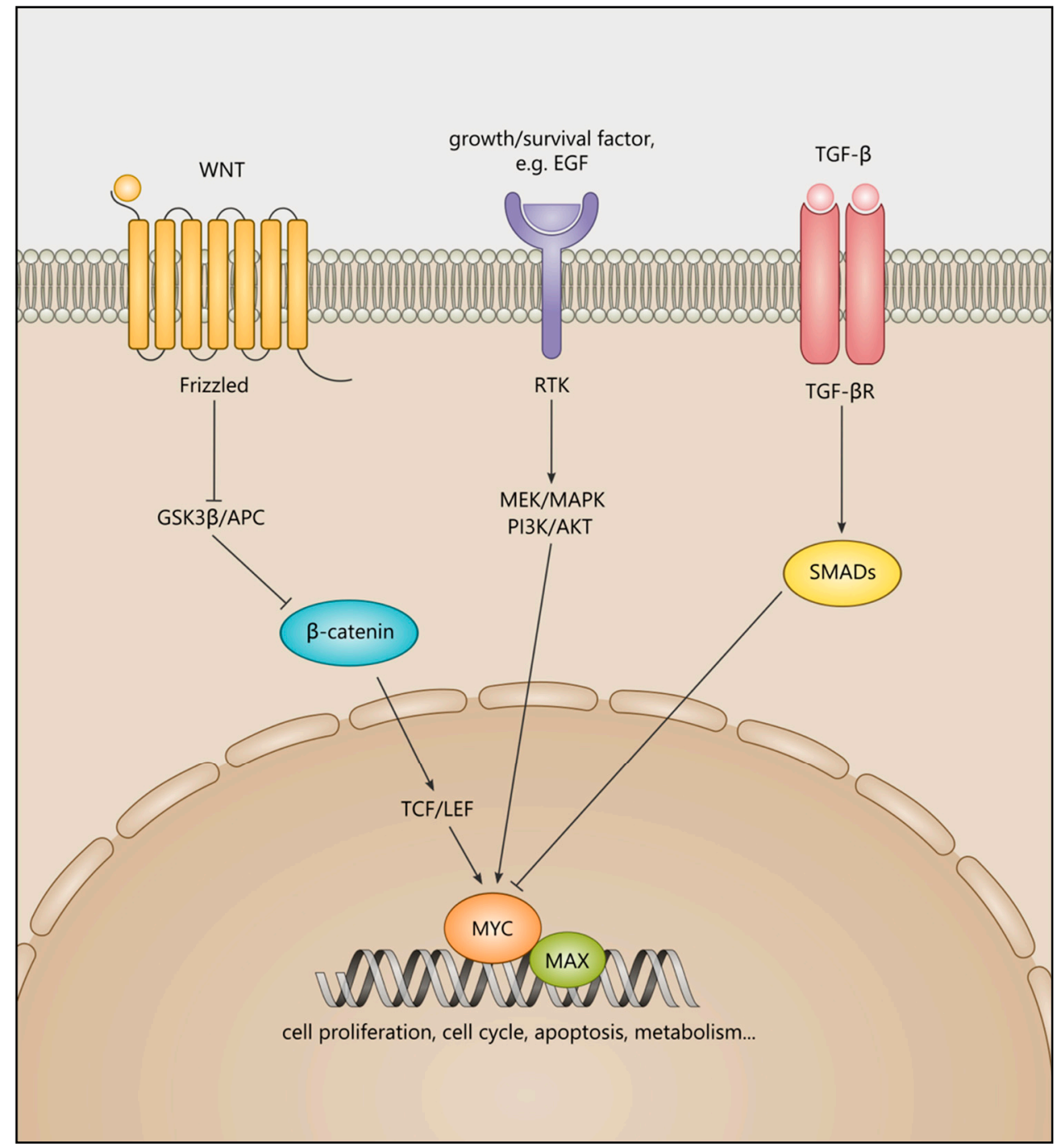

Figure 1. The effects of three signalling pathways converging on MYC activation or repression. A Wnt ligand binds to its receptor frizzled, preventing the phosphorylation of $\beta$-catenin by GSK3 $\beta$ and its subsequent degradation. $\beta$-catenin accumulates in the nucleus and, in association with T-cell factor/ lymphoid enhancer factor (TCF/LEF), activates Wnt signalling target genes, including MYC. The positive input of growth and survival factors including EGF and its downstream mediators, including MEK/MAPK/PI3K/AKT on MYC activation, while TGF- $\beta$ signalling via SMADs can suppress MYC activity. MYC can form a heterodimer with MAX and can govern cell proliferation, apoptosis, and metabolism.

MYC TFs are expressed in normal embryogenesis and play integral roles in influencing normal developmental processes, such as brain development, including the cerebellum [12]. Furthermore, MYC inactivation may be a prerequisite for terminal differentiation, lineage commitment, and cellular quiescence $[13,14]$. For instance, in haematopoietic progenitor cells and skin stem cells, MYC can induce terminal differentiation and lineage commitment $[15,16]$. 
In cancers, however, MYC has also been shown to interact with other oncogenes, such as RAS, in numerous cancers [17]. MYC activation can, when in association with other mutagenic events, drive tumourigenesis. For instance, $M Y C$ expression driven by different enhancers, in association with other mutations, led to leukaemia formation in various B-cell developmental stages [8]. Moreover, alterations to MYC expression and function are found in multiple malignancies, including cancers of the central and peripheral nervous system such as glioblastoma multiforme, and neuroblastoma (NB) $[18,19]$. In many of these cancers, MYC hijacks cellular and molecular programmes through an extensive network of target genes, effectors, regulators, and signalling pathways. MYC has also been implicated in the reprogramming of metabolic states and in promoting angiogenesis, aggressive behaviour, and metastasis in cancers [20-23]. Table 1 shows examples of genes associated with MYC TFs in a panel of cancers.

Table 1. Examples of MYC-associated partners, upstream mediators, or target genes and the malignancies in which they have been identified.

\begin{tabular}{cc}
\hline Cancer Type & $\begin{array}{c}\text { Examples of MYCN/MYC/MYCL-Associated Binding } \\
\text { Partners, Upstream Regulators, Effectors, and Target } \\
\text { Genes and Their Signalling Pathways }\end{array}$ \\
\hline Prostate cancer & Co-occupation with AR at FOXA1 and HOXB13 loci [24] \\
\hline Pancreatic ductal adenocarcinoma & KRAS and YAP [25] \\
\hline Medulloblastoma & SOX2 [26] \\
\hline Neuroblastoma & W-catenin, mir-204 [27,28] \\
\hline Colorectal cancer & Wnt-APC, CAD, UMPS, and CTPS [7] \\
\hline Rhabdomyosarcoma & PAX3-FOXO1 [29] \\
\hline Non-small cell lung cancer & KRAS, IL-23, and CCL9 [30,31]
\end{tabular}

In addition to MYC TFs' roles in cell proliferation, metabolism, and angiogenesis, these TFs may also be involved in lineage plasticity in cancers. Cell plasticity is defined as the ability of a cell to alter its phenotype without genetic mutation in response to environmental factors. It is considered an emerging mechanism of tumour evolution and treatment resistance in cancers [24]. For instance, MYCN-driven, castration-dependent prostate cancer may progress towards a neuroendocrine fate through lineage plasticity and epigenetic reprogramming, reducing therapy efficacy [24].

MYC genes and proteins also interact with long non-coding RNAs (lncRNAs) by regulating various cellular pathways and processes in cancer. Notably, lncRNAs have recently been revealed to target $M Y C$ genes and proteins by regulating either MYC transcription, protein stabilisation, activity, or other molecules involved in MYC expression and activity [32,33]. As we will discuss later in this review, the interaction between MYC and lncRNAs can be complex and fundamental to cancer progression via the regulation of numerous processes, such as proliferation, survival, migration, and invasion.

MYC TFs have also been found to have a central role in cancer by inducing autophagy. For instance, cells following transformation induced by MYC activated autophagy due to mitochondrial stress, inhibiting tumour growth in vitro and in vivo [34]. This study demonstrated that MYC-mediated transformation sensitised cells to autophagy induction by the linamarase/linamarin/glucose oxidase system (lis/lin/GO), which activated the AMPK pathway and upregulated autophagy genes [34-36]. These studies revealed a central role for MYC-mediated cellular functions, signalling, and metabolic pathways.

In this review, we address the role of MYC as a transforming oncogene in multiple cancers and how MYC is influenced by lncRNAs and may be implicated in crucial prosurvival cellular processes such as autophagy. Finally, we discuss both these aspects of MYC pathology to identify novel therapeutic strategies that may be implemented to effectively establish MYC as a valid candidate for onco-therapy. 


\section{Cancers with MYC-Related Functions in Their Pathogenesis}

\subsection{Prostate Cancer}

MYCN is not usually expressed in the epithelial lineage that gives rise to prostate cancer. However, its aberrant expression can, in part, drive neuroendocrine prostate features in advanced prostate cancer by epigenetic reprogramming [24]. A study aimed at understanding the MYCN-triggered epigenetic reprogramming of prostate cancer to neuroendocrine prostate fate, the cistrome, and the transcriptome of these tumours were investigated in vitro, in vivo, and in patient-derived organoids. Genetically modified mice, $\mathrm{Pb}$ - $\mathrm{Cre}+/-$ Ptenfl/fl LSL-MYCN+/+, develop prostate tumours in 100\% of offspring compared with littermates that lack MYCN expression ( $\mathrm{Pb}-\mathrm{Cre}+/-$ Ptenfl/fl LSL-MYCN-/-). In response to castration, $\mathrm{Pb}-\mathrm{Cre}+/-\mathrm{Ptenfl} / \mathrm{fl} \mathrm{LSL}-\mathrm{MYCN}+/+$ mice developed invasive tumours with metastatic features including epithelial-to-mesenchymal transition (EMT) (e.g., indicated by vimentin expression) and the expression of neural markers (e.g., NCAM1) [24]. Furthermore, transcriptional profiling of MYCN-expressing 22Rv1 prostate cancer xenograft models in castrated and non-castrated states revealed that castration led to an increase in expression of neural lineage genes (e.g., SOX11). This observation was also confirmed in LNCaP-MYCN overexpressing cell lines, in which androgen absence led to the differential expression of over $40 \%$ of MYCN target genes (including stem cell and neural lineage differentiation markers). Contrastingly, in the presence of androgen, androgen receptor (AR)-related genes were preferentially expressed [24]. Consistent with the acquisition of an alternative identity, for LNCaP-MYCN expressing cell lines, the MYCN-driven cistrome was revealed to be AR-dependent. In the presence of androgen, $\mathrm{MYCN}$ co-occupied genomic loci with targets of AR, including FOXA1 and HOXB13. In the absence of androgen, the MYCN cistrome was diverted towards promoters of neural stem cell (NSC) genes. In conclusion, MYCN-driven prostate tumours displayed greater aggressiveness, with MYCN driving transcriptional programmes in advanced stages of prostate cancer $[24,37]$.

\subsection{Pancreatic Ductal Adenocarcinoma}

In pancreatic ductal adenocarcinoma (PDAC) originating from exocrine acinar cells, acinar to ductal metaplasia and progression to high-grade neoplasia were instigated upon acquiring Kras mutations [25]. Kras mutant tumours maintained metabolic reprogramming mediated by Myc and increased glycolytic flux and glutamine metabolism to meet the energetic demands of elevated proliferation and redox maintenance, respectively [37]. Yap, a transcriptional regulator, acted as a driver of Kras-mediated PDAC initiation [38], while the roles of Myc, Yap, and Kras mutations in the maintenance of PDAC were investigated using conditional transgenic mouse models. $\mathrm{Kras}^{\mathrm{G} 12 \mathrm{D}}$ and Yap were sequentially activated or deleted using Flp-FRT and tamoxifen-inducible Cre-lox systems, respectively (i.e., FSF$\mathrm{Kras}^{G 12 D /+}, \mathrm{R} 26^{\text {FSF-CreER/dual }}$, Yap flox/flox , and pdx1-Flp) [25]. From a metabolic standpoint, the co-expression of Yap and Myc promoted metabolic gene expression, leading to tumour growth, maintenance, and survival in PDAC [25]. Furthermore, in partnership with TEA domain (TEAD) TFs, Yap promoted Myc transcription and cooperated with Myc in regulating metabolic gene expression. The ablation of Yap led to a metabolic crisis, regression of tumours at early stages, and cell death. Interestingly, in the absence of Yap, Myc expression levels were upregulated by Sox2, resulting in a reversal of the inhibitory effect of Yap deletion on cell proliferation and metabolic gene regulation. This compensatory effect ultimately led to the re-differentiation of neoplastic ductal cells to acinar cells with associated pancreatic enzyme production, highlighting the complexity of MYC-driven metabolic networks [25].

\subsection{Medulloblastoma}

Medulloblastoma is an aggressive paediatric brain tumour classified into the WNT, $\mathrm{SHH}$, group 3, and 4 subtypes. In subgroup 3 of this cancer, somatic MYC alterations and amplifications have been reported, although it remains unclear whether these alterations alone drive tumourigenesis [26]. In a study aimed at understanding the contribution of 
MYC to malignant transformation, lentiviral MYC was transduced into unsorted mouse cerebellum cells, which were subsequently orthotopically transplanted into NOD SCID gamma (NSG) mice, leading to tumour formation. This study also revealed that Sox 2 was required for tumour initiation since the co-expression of endogenous Sox2 with transduced MYC was sufficient to lead to tumourigenesis in vivo [26]. This study also demonstrated that the Sox $2^{+}$cell population expressing Aldh1a1, a protein associated with a cancer stem cell phenotype, generated tumours in vivo, while this capacity decreased with lower or absent expression of Aldh1a1 [26]. Additionally, the expression of lactate dehydrogenase A ( $L D H A)$ positively correlated with MYC expression levels indicative of an unfavourable prognosis in this medulloblastoma subtype [26]. The inhibition of LDHA in vivo led to reduced growth of MYC-driven tumours but not MYC-independent tumours [26]. In conclusion, this study revealed that MYC-induced transformation of Sox $2^{+} / \mathrm{Aldh}_{1} 1^{\text {high }}$ cells led to tumour growth in the postnatal cerebellum in vivo, with characteristics of type 3 medulloblastoma [26].

\subsection{Neuroblastoma}

Risk stratification for NBs is dependent on multiple variables, including MYCN amplification status and age [39]. Of these, MYCN amplification, seen in more than $50 \%$ of high-risk NBs, is the strongest indicator of poor clinical prognosis. The mechanism by which MYCN influences NB development was investigated in a study that analysed the transcriptomic profile, specifically miRNA and mRNA interactions implicated in tumourigenesis, of premalignant sympathetic ganglia and tumours from tyrosine hydroxylase promoter-driven MYCN $\left(\mathrm{TH}-\mathrm{MYCN} \mathrm{CN}^{+/+}\right)$transgenic mice [28]. For instance, mir-204 was shown to suppress a network of oncogenes associated with MYCN, while mir-204 and MYCN mutually repressed each other's expression by binding to the corresponding promoter, in association with relevant transcriptional machinery and repressors [28]. Through this negative repression mechanism, the insertion of miR-204 mimics into MYCN amplified NB cell lines led to a reduced colony-forming capacity. Accordingly, miR-204 was identified as a tumour suppressor and a putative therapeutic agent, since in mouse xenograft experiments, MYCN-amplified cells transduced with an inducible miR-204 construct showed delayed tumourigenesis [28].

\subsection{Colorectal Cancer}

Deregulation of the Wnt-APC pathway can lead to increased levels of MYC in colorectal cancer (CRC) [7]. The role of MYC in metabolic reprogramming of CRC was investigated in a study by Satoh and colleagues in which they compared multi-omics profiles across 275 matched tumour and normal patient tissues. The upregulation of MYC was detected at all stages of cancer progression and resulted in the aberrant regulation of 231 metabolic genes involved in pathways including MAPK signalling, pentose phosphate, and fatty acid metabolism [7]. Interestingly, the most remarkable changes to these metabolic genes, or a metabolic shift, were detected at the adenoma stage and maintained in later stages of the tumourigenic process. Interestingly, the knockdown of $M Y C$ in vitro led to a reversal of the altered metabolism and reduced cell growth. This study provided evidence that MYC, as a regulator of metabolic processes, governed the metabolic reprogramming of CRC by regulating metabolic reactions and a multitude of genes involved in metabolism, such as CAD, UMPS, and CTPS [7]. This finding may impact diagnostic studies.

\subsection{Rhabdomyosarcoma}

Over $40 \%$ of alveolar Rhabdomyosarcoma (RMS) show MYCN amplification associated with improved overall survival. MYCN expression is also characteristic of embryonal RMS, although gene amplification is not a feature in this subtype [40-42]. In a study focused on the mechanisms behind RMS tumourigenesis, immortalised human myoblasts expressing constitutive MYCN and doxycycline-inducible PAX3-FOXO1 (a fusion protein) were grafted orthotopically to immunodeficient mice. Food supplementation with doxycycline 
led to the induction of PAX3-FOXO1 and the formation of RMS tumours. Cells transformed exclusively with PAX3-FOXO1 generated tumours after a longer period of time than those also expressing MYCN. These results suggest cooperation between these two TFs in the early stages of tumourigenesis, leading to an increase in proliferation and the inhibition of the myogenic differentiation programme [29]. Interestingly, the withdrawal of doxycycline from animal diets after tumour formation led to tumour regression followed by tumour recurrence, suggesting that, while RMS tumours are dependent on PAX3-FOXO1, these may relapse through PAX3-FOXO1-independent pathways [29].

\subsection{Non-Small Cell Lung Cancer}

MYC and KRAS act as downstream conduits for other oncogenic drivers, enhancing the process of tumourigenesis in lung adenomas and their transformation to invasive and proliferative adenocarcinoma of the lung [30,31]. A study by Soucek and colleagues, focusing on an endogenous Myc-switchable Kras G12D (LSL-Kras, TRE-Omomyc, and CMVrtTA) mouse model of lung adenocarcinoma showed that Kras ${ }^{G 12 D}$ expressing mice developed bronchiolar hyperplasia [31]. The Kras-dependent bronchiolar hyperplasia regressed with Omomyc expression, suggestive of a role for Myc in maintaining Kras ${ }^{\mathrm{G} 12 \mathrm{D}}$-driven lung tumours. Mechanistically, Omomyc expression inhibited cellular proliferation by downregulating Myc expression. Interestingly, Myc inhibition in normal, healthy tissues with a rapid turnover, such as the epidermis, testis, and intestinal tract displayed reduced proliferation. Despite these effects, the systematic suppression of Myc was tolerated since the reversal of Myc inhibition led to rapid recovery of the affected tissues [31].

In a follow-up study using LSL-Kras G12D Rosa26-LSL-MycERT2 transgenic mice, with constitutive expression of $\mathrm{Kras}^{G 12 D}$ and inducible expression of $M y c E R^{T 2}$, it was proposed that, while the $K r a s{ }^{G 12 D}$ mutation alone was sufficient to induce preneoplastic lesions, the additional activation of Myc led to rapid acceleration of tumourigenesis, hence transforming indolent tumours to adenocarcinomas [30]. This group also investigated the effect of $M y c E R^{T 2}$ activation on angiogenesis and the tumour microenvironment, revealing that Myc governed processes such as inflammation and angiogenesis through its noncell-autonomous effectors, IL-23 and CCL9, which induce microenvironment alterations. Consistently, the blockage of CCL9 alone led to the extensive inhibition of macrophage influx mediated by Myc, loss of T cells, and the prevention of new blood vessel formation. In contrast, the inhibition of IL-23 led to tumour cell death by apoptosis; a reduction in proliferation; and the recruitment of $\mathrm{B}, \mathrm{T}$, and NK cells [30]. Ultimately, this study pointed towards the marked capacity of Myc to suppress innate and adaptive immunity in tissues and to induce adenocarcinomas from indolent tumours.

In summary, we reviewed MYC-driven regulatory networks in multiple cancers and highlighted potential novel therapeutic axes involved in each specific cancer type. Due to the difficulty in directly targeting MYC for therapy, these studies were invaluable and could lay the groundwork for successful MYC-focused treatment strategies.

\section{MYC and Long Non-Coding RNAs (LncRNAs) in Cancer}

\subsection{LncRNAs in Cancer as Novel Biomarkers and Therapeutic Targets}

LncRNAs have been shown to interact with TFs, including MYC, often via direct regulation of their expression, protein stabilisation, and activity or via indirect regulation of other molecules involved in their expression and activity [32,33,43]. LncRNAs are noncoding RNA (ncRNA) molecules longer than 200 nucleotides and are the most abundant class of non-coding transcripts. LncRNAs are aberrantly expressed in several malignancies, and both the lncRNAs and the mechanisms associated with the complex structures they can form, allowing for their interaction with a large number and variety of molecules, have been extensively studied in the context of cancer biology and treatment [33]. Notably, lncRNAs are often expressed in a tissue- and disease-specific manner with critical functions in several cancers and have great potential as novel biomarkers and therapeutic targets in cancer [44-46]. Consistently, lncRNAs have been isolated from patient's biological fluids, 
either free or packed into exosomes $[47,48]$. Clinical trials are currently recruiting patients for lncRNA-based cancer diagnostics (URL: https: / / clinicaltrials.gov/ct2 / show /NCT0 3830619) (accessed 15 February 2019); a trial focused on using serum exosomal lncRNAs as putative biomarkers in lung cancer diagnostics. Other lncRNAs have already been approved for clinical use; for example, PCA3 is currently used in the diagnosis of prostate cancer [49]. Additionally, most lncRNAs are upregulated in specific oncogenic pathways, and their inhibition could act alone or in combination with other treatments to improve patient response. Several methods of lncRNA inhibition include antisense oligonucleotides (ASOs), single-stranded DNA polymers, locked nucleic acids (LNA), and morpholinos (Table 2) [50-56].

Table 2. Strategies to modulate MYC-driven gene networks concerning regulatory, lncRNAs, and autophagy-related processes and networks.

\begin{tabular}{|c|c|c|c|}
\hline Target & $\begin{array}{l}\text { Mechanism of } \\
\text { Regulation }\end{array}$ & Outcome & Malignancy \\
\hline MYC & $\begin{array}{l}\text { Antisense oligonucleotide } \\
\text { morpholinos }\end{array}$ & $\begin{array}{c}\text { Reduction of pro-angiogenic proteins } \\
\text { and metastasis }\end{array}$ & Lung cancer [55] \\
\hline $\begin{array}{c}\text { linc00485/miR-298/MYC } \\
\text { network }\end{array}$ & linc00485 silencing & Reduction of cancer cell proliferation & Lung cancer [57] \\
\hline $\begin{array}{l}\text { Linc00261/p300/CBP/MYC } \\
\text { network }\end{array}$ & Linc00261 overexpression & $\begin{array}{l}\text { Inhibition of cancer cell proliferation, } \\
\text { migration, and metastasis in vitro }\end{array}$ & Pancreatic cancer [58] \\
\hline $\begin{array}{l}L P P-A S 2 / m i R-7- \\
5 p / E G F / \mathrm{MYC}\end{array}$ & $L P P-A S 2$ knockdown & Tumour growth inhibition & Glioma [59] \\
\hline $\begin{array}{c}\text { MYC/miR-150/EPG5 } \\
\text { (autophagy) }\end{array}$ & $\begin{array}{l}\text { Inhibition of } M Y C / m i R-150 \\
\text { expression }\end{array}$ & $\begin{array}{l}\text { Reduced cell growth in vitro and } \\
\text { in vivo }\end{array}$ & NSCLC [60] \\
\hline $\begin{array}{l}\text { AMBRA1-PP2A/MYC } \\
\text { regulated by mTOR }\end{array}$ & mTOR inhibition & $\begin{array}{l}\text { MYC protein degradation and } \\
\text { reduction in cell proliferation }\end{array}$ & $\begin{array}{c}\text { Breast and lung carcinoma cell } \\
\text { lines [61] }\end{array}$ \\
\hline MYC activation of & & Reduced MYC-induced autophagy & Human P493-6B \\
\hline $\begin{array}{c}\text { PERK/eIF } 2 \alpha / \text { ATF } 4 \text { arm of } \\
\text { the UPR }\end{array}$ & Autophagy inhibition & $\begin{array}{l}\text { and tumour formation, Increase in } \\
\text { MYC-dependent apoptosis }\end{array}$ & $\begin{array}{l}\text { lymphoblastoid cell line and } \\
\text { MEF cells [62] }\end{array}$ \\
\hline CMA/ CIP2A/ MYC & CMA activation & Proteasomal degradation of MYC & MEF cells [63] \\
\hline
\end{tabular}

\subsection{Oncogenic IncRNAs Promote MYC Expression and Activity in Cancer}

Several studies have focused on the roles of lncRNAs in MYC regulation in cancer; in recent years, novel mechanisms and interactions that are of clinical relevance have been characterised. One notable mechanism is the mutual regulation of lncRNAs and MYC via intricate feedback loop mechanisms. LncRNAs are often upregulated in cancer and can promote oncogenic pathways and phenotypes. For example, a regulatory network modulated by MALAT1 in thyroid cancer has shown that this lncRNA acts as a competing endogenous RNA (ceRNA) by sequestering miR-204 (Figure 2A) [32]. In Figure 2A, MALAT1 and miR-204 have been referred to as lncRNA and miRNA, respectively. Specifically, this study revealed that, in thyroid cancer, MALAT-1 and insulin-like growth factor 2 mRNA binding protein 2 (IGF2BP2), a member of RNA binding proteins, were expressed while mir-204 was expressed poorly. IGF2BP2 was identified as a target of mir-204 and the regulatory loop comprising these players was identified as follows: MALAT1 selectively bound to mir-204, preventing mir-204 from binding IGF2BP2 and leading to IGF2BP2 upregulation. As a result, IGF2BP2 could recognise the N6-methyl-adenosine (m6A) modification of MYC RNA and could consequently increase its expression. This regulatory network resulted in increased proliferation, migration, and invasion of thyroid cancer cells [32]. Hence, targeting lncRNAs may simultaneously affect numerous downstream oncogenic pathways, including MYC, representing a valid therapeutic approach.

Linc00485 is another example of an oncogenic lncRNA for which expression is upregulated in human lung cancer and is associated with metastasis and relapse [57]. Notably, linc00485 was associated with the tumour-node-metastasis (TNM) stage in this cancer, and linc00485 overexpression increased the proliferation, migration, and invasiveness of 
lung cancer cells by directly sequestering miR-298, which targeted MYC. The significance of the linc00485/miR-298/MYC axis in vivo, demonstrated using xenotransplantation of lung cancer cell lines including A549, revealed that linc00485 silencing using short hairpin lincRNA resulted in reduced cancer cell proliferation. Collectively, this study showed a crucial regulatory link involving MYC, miRNAs, and lncRNAs while offering a promising therapeutic strategy (Table 2) [57].

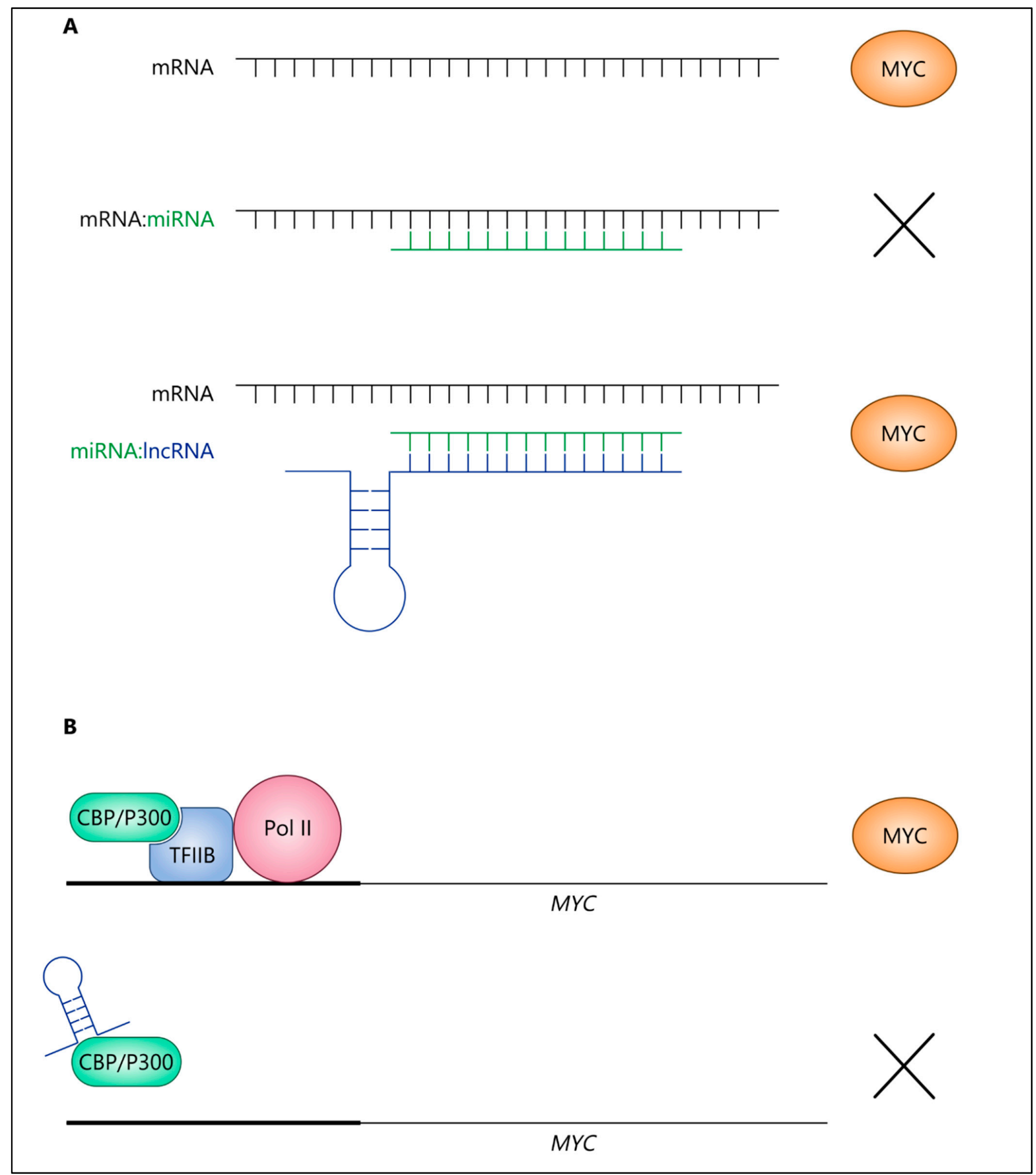

Figure 2. Regulatory loops involving lncRNAs and MYC. (A) A lncRNA (e.g., MALAT1) acting as a competing endogenous RNA by sequestering miRNA (e.g., miR-204), allowing for the production of MYC. (B) The physical interaction between a $\operatorname{lncRNA}$ (e.g., linc00261) prevents the recruitment of p300/CBP to the promoter region of MYC, thereby repressing MYC expression. 


\subsection{LncRNAs Repress MYC under Certain Conditions}

LncRNAs are not exclusively oncogenes and can also act as tumour suppressors in specific circumstances. An example is linc00261, which acts as a tumour suppressor in pancreatic cancer via transcriptional regulation of MYC expression. Linc00261 directly binds to the bromodomain of the transcriptional co-factor p300/CBP (a member of the transcriptional co-activator family), preventing its recruitment to the promoter region of $M Y C$, thereby epigenetically repressing MYC expression (Figure 2B, linc0026 is lincRNA) [58]. Finally, linc0026 overexpression inhibited pancreatic cancer cell proliferation, migration, and metastasis in vitro (Table 2) [58].

An alternative mechanism of linc00261 activity in pancreatic cancer is via targeting of $m i R-222-3$, leading to the modulation of MYC expression both via miRNA regulation and sequestration of insulin-like growth factor 2 mRNA binding protein 1 (IGF2BP1). Mechanistically, linc00261 was downregulated by methylation of the CpG islands (regions of DNA with greater CG content) associated with its promoter, and the enhancer of Zeste 2 Polycomb repressive complex 2 subunit (EZH2) mediated the methylation of lysine 27 of histone 3 (H3K27) (also known as permissive histone marks) deposited to its promoter region. This suggests a complex interaction between lncRNAs and epigenetics in the regulation of oncogenes such as MYC [58,64].

Another example, $P V T 1$ lncRNA, was a regulator of the transcription of key oncogenic pathways, such as TGF $\beta /$ SMAD and Wnt/ $\beta$-catenin, acting as an enhancer for MYC [65]. Specifically, the PVT1 locus impacted the expression of essential genes in both pathways while the aberrant methylation of $P V T 1$ lncRNA also led to alterations in MYC expression. Therefore, it is not surprising that the PVT1 lncRNA expression was associated with a poor prognosis for CRC patients [65].

On the contrary, in lung adenocarcinoma, the PVT1b isoform is expressed downstream of MYC and is induced by DNA damage and oncogenic signals, thus acting as a tumour suppressor [66]. Once transcribed, PVT1b accumulated near the MYC transcription start site, contributing to the suppression of MYC expression in cis, a mechanism triggered by P53 [66]. It follows that PVT1b inhibition resulted in an escalation of MYC expression and activity, leading to an increase in cell proliferation; indeed, loss of PVT1b in vivo promoted tumour growth [66]. In conclusion, the P53-induced lncRNA-mediated changes in transcription may allow for rapid adaptation and response to cellular stress.

\subsection{Mutual Regulation of IncRNAs and MYC via Feedback Loops}

LncRNA-MYC feedback loop mechanisms have been studied in different malignancies with biological and clinical relevance to cancer phenotypes. An interesting example may be metastasis suppressor 1 (MTSS1) and its lncRNA. In pancreatic cancer, the lncRNA MTSS1-AS upregulated its sense gene, metastasis suppressor 1 (MTSS1), by acting as a scaffold/decoy between E3 ubiquitin-protein ligase STIP1 homology and U-box containing protein 1 (STUB1), which earmarks proteins for proteasomal degradation and the transcription regulator myeloid zinc finger 1 (MZF1). MZF1 inhibited MTSS1 expression by binding its promoter (Figure 3A, MTSS1-AS, MTSS1, and MZF1 are lncRNAs encoded by gene $A-A S$, gene $A$, and regulatory protein, respectively), and MTSS1-AS-induced ubiquitination-mediated degradation of MZF1 leads to the upregulation of MTSS1 [67]. Furthermore, extracellular acidity reduced MTSS1-AS levels, thereby stabilising MZF1 and promoting metastasis [67].

MYC regulation was upstream of this pathway, and MYC binds the initiator elements of the MTSS1-AS promoter, thereby inhibiting lncRNA transcription in association with relevant transcriptional machinery [67]. In turn, MTSS1-AS repressed the MZF1-mediated transcription of $M Y C$, thereby forming a negative feedback loop between MTSS1-AS and MYC in acidic pancreatic cancer cells, with overexpression or knockdown of MTSS1$A S$ leading to the inhibition or promotion of $M Y C$ expression, respectively (Figure 3B, MTSS1-AS, MTSS1, and MZF1 are lncRNAs encoded by gene $A-A S$, gene $A$, and regulatory protein, respectively). 


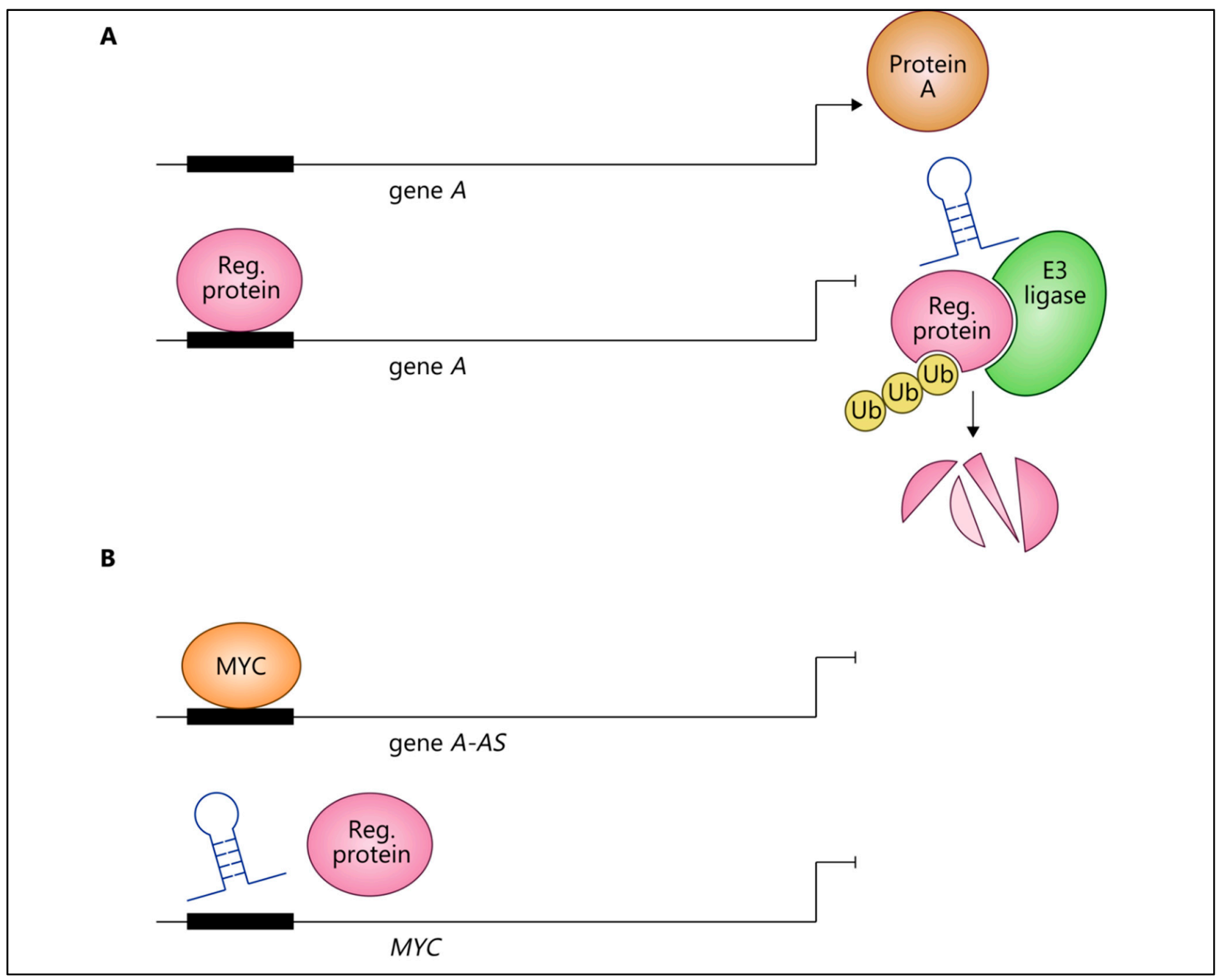

Figure 3. A negative feedback loop involving MYC, lncRNAs, and ubiquitin ligase. (A) LncRNA (encoded by gene $A$ - $A S 1$, e.g., MTSS1-AS1) upregulated the expression of gene A (e.g., MTSS1 gene) acting as a scaffold between E3 ligase and a regulatory protein (e.g., MZF1), leading to ubiquitination-mediated degradation of the regulatory protein; hence, protein A (e.g., MTSS1) was produced. The regulatory protein (e.g., MZF1) inhibited gene A (e.g., MTSS1 gene) expression by binding its promoter. (B) MYC inhibited the lncRNA (e.g., MTSS1-AS1) by binding its initiator elements (gene A-AS, e.g., MTSS1-AS1). In turn, the IncRNA (encoded by gene A-AS, e.g., MTSS1-AS1) inhibited MYC expression by impairing its regulatory protein-mediated transcriptional activation. Reg. = regulatory.

Finally, lncRNA-MYC feedback loops included LPP antisense RNA-2 (LPP-AS2), a lncRNA that was found to be upregulated in glioma. Specifically, LPP-AS2 sequestered mir7-5p, thereby increasing the expression of EGFR and the downstream PI3K/AKT/MYC axis, promoting the transcription of MYC, via this positive feedback loop. In turn, MYC bound directly to the promoter of LPP-AS2 [59]. Depletion of the LPP-AS2/miR-7-5p/EGFR/MYC axis reduced glioma cell proliferation and invasion, and triggered apoptosis. In vivo $L P P-A S 2$ knockdown inhibited tumour growth, whereas LPP-AS2 overexpression had the opposite effect [59]. The oncogenic activity of $L P P-A S 2$ in this positive feedback loop may be a target for therapeutic interventions (Table 2) [59].

To summarise, we reviewed the regulatory complexity surrounding the circuits comprising of MYC and various lncRNAs, miRNA, and signalling pathways. LncRNAs can act as oncogenes by increasing MYC expression and activity or by inhibiting MYC expression. This regulation of MYC function is dependent on multiple positive and negative feedback loops. The enhanced understanding of these regulatory networks could pave the way to the effective targeting of MYC-driven regulatory networks and could introduce lncRNAs as novel biomarkers in cancers and putative therapeutic targets. 


\section{MYC and Autophagy \\ 4.1. MYC, Autophagy, and Cellular and Molecular Processes in Cancers}

Macro-autophagy, hereafter referred to as autophagy, is a major degradation pathway for many organelles, toxic aggregates, and long-lived proteins. In this process, fractions of the cytoplasm are engulfed in a double-membrane structure, also known as an autophagosome. This structure is then fused with lysosomes, allowing for the degradation of its content. MYC, along with other genes such as mTOR, Beclin-1, p53, PTEN, p62, MIF, HMGB1, RAC3, SRC3, NF-2, MEG3, LAPTM4B, and BRAF play essential roles in autophagy-induced tumourigenesis and drug resistance, a new focus of drug development efforts [68]. Toh and colleagues showed that MYC was involved in autophagosome formation in the early stages of autophagy rather than in its degradation and that MYC-driven modulation of autophagy occurs via the JNK1-Bcl2 pathway and ROS (Figure 4). The siRNA-mediated knockdown of MYC inhibited autophagy in human embryonic kidney (HEK293) cells, resulting in an accumulation of the autophagy substrate p62 (SQSTM1/sequestome1, an autophagy receptor, and signalling adapter). Hence, MYC inhibition led to defective autophagosome formation and reduced the clearance of essential autophagy substrates [69]. This study pointed towards the additional benefit of MYC modulation on autophagic processes, especially in autophagy-induced therapy resistance.

Moreover, MYC-induced alterations in autophagy can impact tumourigenesis, whereby the dysfunction of MYC-mediated autophagy contributed to non-small cell lung cancer (NSCLC) development [60]. In NSCLC, inhibiting MYC/miR-150 expression greatly reduced cell growth in vitro and in vivo (Table 2) [60]. In miR-150 overexpressing cell lines, a dysfunction in autophagic flux was observed, as shown by higher numbers of autophagosomes and lower numbers of autolysosomes. $m i R-150$ inhibited the fusion of autophagosomes and lysosomes by directly repressing EPG5, a gene essential for autophagosomal maturation, consequently promoting NSCLC development. Since autophagy deficiency caused the accumulation of damaged mitochondria, it was not surprising that ROS levels were increased in miR-150 overexpressing A549 and H1299 NSCLC cells [60].

In parallel with the aforementioned reports, numerous studies have alluded to the association of multiple factors with the autophagic processes that may affect MYC protein stabilisation. Noteworthily, MYC protein stability is defined by the interaction between two phosphorylation sites, serine 62 and threonine 58 (by ERK and glycogen synthase kinase-3 $\beta$, GSK3 $\beta$, respectively). Serine 62 phosphorylation leads to MYC stabilisation but promotes the phosphorylation of threonine 58, destabilising the protein [70]. Here, we focus on two examples.

In osteosarcoma, polo-like kinase 1 (PLK1, a serine/threonine protein kinase) and MYC promote cell proliferation through the autophagic pathway [71]. PLK1, a protein kinase, is a major driver of proliferation and growth that correlated with poor prognosis when expressed in this cancer. The knockdown of MYC led to decreased LC3-II/LC3-I (standard markers of autophagosomes) and autophagy-related protein 7 (Atg7) as well as defects in autolysosomal degradation. Similarly, the knockdown of PLK-1 resulted in significantly decreased autophagy markers, such as LC3-II/LC3-I and Atg5, in parallel with SQSTM1 accumulation and defects in the autolysosomal pathways. Moreover, PLK-1 contributed to MYC protein stabilisation while PLK1 inhibition led to a significant loss of MYC abundance. Consequently, this caused a marked delay in xenograft tumour growth in mice treated with the PLK-1 inhibitor BI2536, with a lower mean tumour volume compared with the control group [71].

Another protein with a role in autophagy initiation is AMBRA1, a scaffold protein that is a downstream target of mTOR, a major regulator of autophagy. This protein was found to play a tumour suppressor role by promoting MYC dephosphorylation and degradation in lung and breast cancer cell lines. Disruption of the Ambra1 locus induced MYC hyperphosphorylation, leading to tumour hyperproliferation and tumourigenesis. Moreover, when mTOR was inhibited, AMBRA1 enhanced the interaction between MYC and its phosphatase PP2A, consequently reducing cell proliferation (Table 2) [61]. From 
these studies, it is possible to put forth PLK1 and AMBRA1 as valuable candidates for therapies aimed at targeting MYC protein stability.

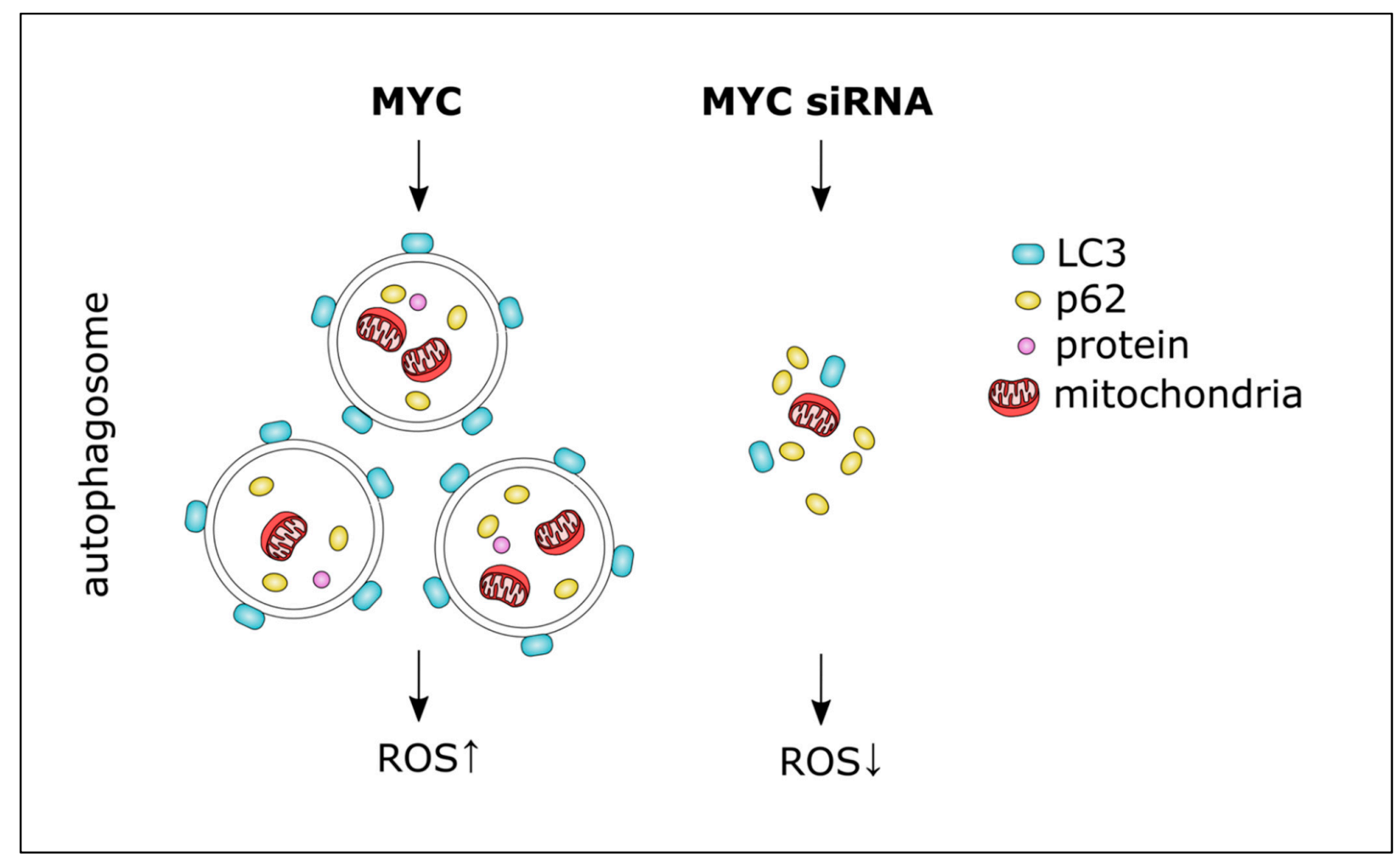

Figure 4. MYC and autophagy. MYC was involved in autophagosome formation whereby siRNA-mediated knockdown of MYC inhibited autophagy, resulting in the accumulation of the autophagy substrate p62. MYC is known to trigger ROS accumulation.

In addition to the examples above, MYC may also be associated with the pathway connecting the endoplasmic reticulum (ER) stress and autophagy. Hart and colleagues showed that ER stress-mediated autophagy stimulated MYC-dependent transformation and tumour growth. Specifically, they showed that MYC and MYCN activated the PERK/eIF2 $\alpha /$ ATF4 arm of the unfolded protein response (UPR) (one of the three arms of UPR) in the P493-6 human lymphoblastoid cell line and mouse embryonic fibroblast (MEF) cells, resulting in increased cell survival via the induction of autophagy (Table 2) [62]. The inhibition of PERK led to reduced MYC-induced autophagy and a significant decrease in tumourigenesis, while the inhibition of autophagy increased the level of apoptosis in an MYC-dependent manner. Blocking ER stress was sufficient to restore normal levels of protein synthesis and consequently reduced autophagy. This link between UPR, ER stress, and autophagy may provide an attractive therapeutic target [62].

\subsection{Chaperone-Mediated Autophagy (CMA) and Mitophagy Link with MYC}

MYC has also been linked with another form of autophagy, chaperone-mediated autophagy (CMA), a selective form of protein lysosomal degradation (Table 2). In most cancers, CMA is upregulated and is essential for tumour growth [72]. Kon and colleagues revealed a novel tumour-suppressor role for CMA in MEF cells, where CMA inhibited the oncogenic activity of MYC by promoting its proteasomal degradation. Mechanistically, CMA triggered MYC destabilisation by regulating CIP2A degradation. CIP2A inhibited a phosphatase that dephosphorylated MYC at Ser62, preventing the ubiquitination and subsequent degradation of MYC (Table 2). Naturally, blocking CMA led to reduced degradation of CIP2A and increased stability of MYC, acting a as potential preventative strategy in cancer initiation (Figure 5, CIP2A is referred to as a regulatory protein) [63]. 


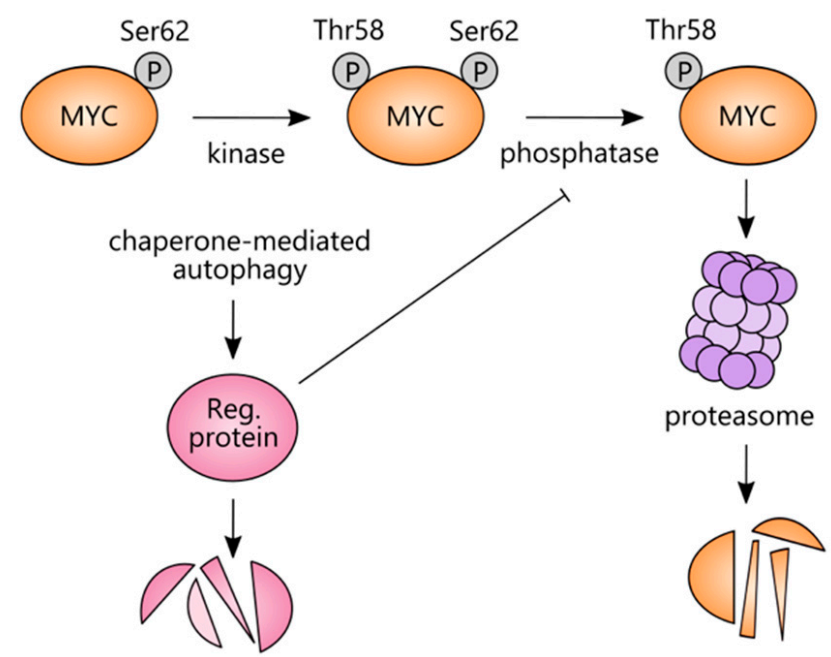

Figure 5. CMA and MYC protein stability. A phosphatase removes phosphoserine 62 from MYC, rendering it unstable and susceptible to proteasomal degradation. This phosphatase may be suppressed by a regulatory protein (e.g., CIP2A) that can, in turn, be degraded by CMA-associated processes. Reg. = regulatory.

Consistently, other studies have shown a link between MYC and mitophagy, a process of selective degradation of mitochondria by autophagy following stress or damage [73]. The mild and sustained hydrogen peroxide treatment induced Parkin-mediated mitophagy and reduced the accumulation of GSK3 $\beta$ in the nucleus, thus decreasing the phosphorylation of MYC. The levels of $m i R-106 b-93-25$ cluster, which was downstream from MYC, were elevated, and this cluster inhibited the mitophagy-associated proteins (e.g., OPTN) to protect against excessive mitophagy, ultimately leading to cell death due to bioenergetic collapse [74,75]. This suggested that miRNAs targeting mitophagy-associated proteins were essential for cell survival and were a mechanism of mitophagy control.

A connecting piece of the puzzle is the link between mitophagy, autophagy, and a membrane protein. A study of MYC-driven lymphomagenesis found that Bax-interacting factor 1 (Bif-1), a member of the membrane curvature-driving endophilin protein family, also known as SH3GLB1, plays a role in apoptosis, autophagy, and mitophagy [76]. Bif-1 was found to play a crucial role in the maturation of nascent autophagosomes during mitophagy to maintain chromosomal stability [76]. Bif-1 haploinsufficiency in the E $\mu-M Y C$ mouse model (a widely used model of MYC-driven malignancy) accelerated MYC-driven lymphomagenesis by suppressing mitophagy and resulted in increased mitochondrial mass within cells at the premalignant state of MYC-induced lymphoma. Since the accumulation of damaged mitochondria (by suppressing autophagy) led to ROS generation and DNA damage accumulation, improper mitochondrial clearance was likely the mechanism behind the promotion of chromosomal instability induced by the loss of Bif- 1 in $M Y C$-induced lymphoma [76].

In summary, in this section, we discussed the interplay between MYC regulatory networks with crucial cellular and molecular processes. We reviewed that MYC was involved in autophagosome formation. Moreover, MYC functional alterations in autophagic processes could contribute to tumourigenesis. We also revealed the role of multiple proteins affecting MYC protein stability. Finally, we investigated UPR, CMA, and mitophagy as cellular processes that may impact MYC functions and stability.

\section{Discussion: Novel Treatment Options for MYC-Driven Malignancies in Light of the Topics Discussed}

Chemotherapy has been instrumental in the treatment of MYC-driven cancers. However, a major caveat with these approaches is the non-discriminatory targeting of prolif- 
erating cells triggering widespread off-target effects. Thus, these methods are gradually replaced by more targeted and effective treatment modalities that rely on the specific targeting of factors that lead to the tumour's initiation, propagation, and progression. One example of this is the notion of "oncogene addiction", whereby, in theory, the genetic inhibition of oncogenes such as MYC is sufficient to cause cell death and reduced tumour burden. Additionally, due to the role of this oncogene in development, regulatable transgenic systems have been critical to these observations, allowing for a better understanding of the effects of de novo activation or inactivation of MYC [77]. For instance, in the context of preclinical mouse models, transcriptional activation of MYC in an inducible $c-M y c E R^{\mathrm{TM}}$ mouse model of the epidermis resulted in papillomatosis, blood vessel formation, apoptosis, and precancerous lesions. Inversely, the lesions regressed upon tamoxifen removal and MYC inactivation [77]. This observation supported the idea that transient inactivation of an oncogene such as MYC can be considered a viable therapeutic strategy.

The regulation of MYC can also be achieved on a transcriptional level whereby the BET bromodomain protein, BRD4, interacts with the positive elongation factor complex $\mathrm{b}(\mathrm{p}-\mathrm{TEFb})$, which is regulated by MYC [78]. Therefore, the BET bromodomain inhibitor, JQ1, was studied in multiple myeloma (MM) for its capacity to inhibit MYC-dependent transcription. In MM, the rearrangement of MYC via a translocation is a frequently occurring genetic alteration while the activation of MYC can be observed in over half of MM cases [79]. In a panel of MM cell lines, JQ1 treatment led to an increase in cells arrested in the G0/G1 phase of the cell cycle and cellular senescence (marked by B-galactosidase expression). Still, only modest levels of apoptosis were detected [79]. In an orthotopic mouse xenograft model, JQ1 treatment led to a decreased disease burden and increased overall survival of these mice compared to controls [79]. Furthermore, MYC-dependent processes such as glycolysis were also affected by JQ1. Collectively, these results pointed towards the feasibility of specifically targeting MYC and its extensive targets [79].

On a different note, MYC protein can also be modulated by various molecules [43,80]. For example, the interaction between lncRNA LUCAT1 and Nuclein (NCL, an inhibitor of MYC) is interesting. LUCAT1 interacted with NCL via its G-quadruplex structure (a structure formed by guanine rich nucleic acids) in CRC and promoted MYC expression and cancer cell proliferation. Interestingly, in knockdown and rescue experiments, cells lacking LUCAT1 displayed reduced MYC levels, while this phenotype could be rescued by NCL knockdown [80].

Furthermore, it has proven possible to target MYC with morpholinos in lung and prostate cancers; the latter has been tested successfully in preclinical models and clinical trials $[55,56]$. Notably, morpholinos and other ASOs have been studied as successful approaches to target lncRNAs, some of which are regulated by or regulate MYC and can also be correlated with MYC via mutual modulation of expression and function $[59,67,81]$. Since lncRNAs can be upregulated under specific pathological conditions, the indirect targeting of MYC oncogenic functions via direct targeting of lncRNAs should, in principle, lead to improved treatment efficacy and reduced side effects. In this context, lncRNAmediated upstream regulation of MYC should be further investigated, such as modulation of the MALAT1/mir-204 axis in thyroid cancer, which, as reviewed in Section 3.1, could be a plausible method of reducing levels of MYC. We reviewed that MALAT1 increased IGF2BP2 and MYC expression by binding to mir-204 [32], a process that can be manipulated as a therapeutic strategy by inhibiting MALAT1 or increasing mir-204 levels. Other lncRNAs such as linc00261, linc00485, and LUCAT1 may also show potential for regulating MYC levels and tumour-associated functions via their modulation $[43,57,58]$.

MYC-driven gene regulatory networks also apply to the axis of miRNA and autophagy networks and, hence, may be exploited for treatment. For example, the involvement of $m i R-27 b-3 p$ in MYC-induced autophagy was investigated in CRC. In this study, CRC cells became resistant to oxaliplatin (OXA) through the $M Y C / m i R-27 b-3 p / A T G 10$ axis [82]. This study found that MYC, in association with relevant transcriptional machinery and repressors, repressed the transcription of $m i R-27 b-3 p$, upregulating autophagy and leading 
to chemoresistance. Furthermore, $m i R-27 b-3 p$, upon inhibiting autophagy, resensitised chemoresistant CRC cells to OXA through Atg10 suppression. Indeed, siRNA-mediated ATG10 suppression inhibited the proliferation of SW480 colon adenocarcinoma cells and resensitised them to OXA [82]. Perhaps the most exciting finding of this study was the dissection of the MYC/miR-27b-3p/ATG10 axis for therapy [82].

In line with the significance of various autophagic pathway components, including lysosomes in the completion of autophagy, lysosomal protein transmembrane 4 beta (LAPTM4B), a potential oncogene was investigated with respect to MYC regulatory networks in breast cancer [83]. For instance, LAPTM4B was shown to play a critical role in tumour proliferation; metastasis; autophagy inhibition; and resistance to chemotherapeutic drugs such as doxorubicin, cisplatin, and paclitaxel [83]. LAPTM4B-35 (the protein product) activated the PI3K/AKT signalling pathway leading to the phosphorylation of GSK $3 \beta$, resulting in the attenuation of $M Y C$ degradation and consequently promoting the proliferation of carcinoma cells [84]. This significant finding suggested that LAPTM4B-35 may be an attractive target for reducing MYC levels. Additionally, the downregulation of LAPTM4B-35 by RNAi decreased the efflux of chemotherapeutic agents, hence sensitising chemical therapy [84]. These studies have brought together MYC regulatory networks, lysosomal proteins, drug resistance, and autophagy as drug therapy candidates.

Finally, in addition to autophagy, the interaction of MYC with mitophagy and cellular metabolism was a focus of our review and may provide valuable biomarkers and therapeutic approaches in cancers. For instance, for diffuse large B-cell lymphoma (DLBCL), MYC induces abnormal choline metabolism by transcriptionally activating the essential gene, phosphate cytidylyltransferase 1 choline- $\alpha$ (PCYT1A), a gene involved in the synthesis of phosphatidylcholine [85]. The lipid-lowering alkaloid Berberine (BBR) exhibited anti-lymphoma activity by inhibiting MYC-driven PCYT1A expression and by activating mitophagy-dependent necroptosis, both in vitro and in vivo. B-cell lymphoma cell necroptosis was reversed by treatment with the mitophagy inhibitor Mdivi-1 [85]. This study revealed that the effective manipulation of MYC requires an understanding of the meshwork of cell death and survival, and autophagic and mitophagy processes.

In conclusion, the effective (in)direct targeting of MYC TFs through their regulatory networks with cellular and molecular networks in MYC-driven malignancies has shown promising potential for cancer therapy over traditional methods. In this review, we dissected numerous MYC networks associated with lncRNAs, autophagy, and mitophagy, in which specific targeting of MYC was achieved on transcriptional, epigenetic, miRNA regulation, or protein levels. These interactions and mutual regulations could be viewed as unexplored areas of MYC targeting that may warrant a more in-depth investigation with the objective of future clinical implementation. These strategies are in line with reducing off-target effects of non-specific and non-context-specific targeting of these TFs in the broader context of physiological and pathological networks and processes.

Author Contributions: L.J., P.P., T.I., R.M.T., J.A.W., J.P., M.L.C., S.D.T., G.V.G., and L.T. wrote, reviewed, and edited the paper. All authors have read and agreed to the published version of the manuscript.

Funding: The author(s) received no specific funding for this work.

Acknowledgments: G.V.G. acknowledges support from the NIHR Birmingham ECMC; NIHR Birmingham SRMRC; Nanocommons Horizon 2020-EU (731032); the NIHR Birmingham Biomedical Research Centre; and the MRC HDR UK (HDRUK/CFC/01), an initiative funded by UK Research and Innovation, Department of Health and Social Care (England), and the devolved administrations and leading medical research charities. The views expressed in this publication are those of the authors and not necessarily those of the NHS, the National Institute for Health Research, the Medical Research Council, or the Department of Health.

Conflicts of Interest: The authors declare no conflict of interest. 


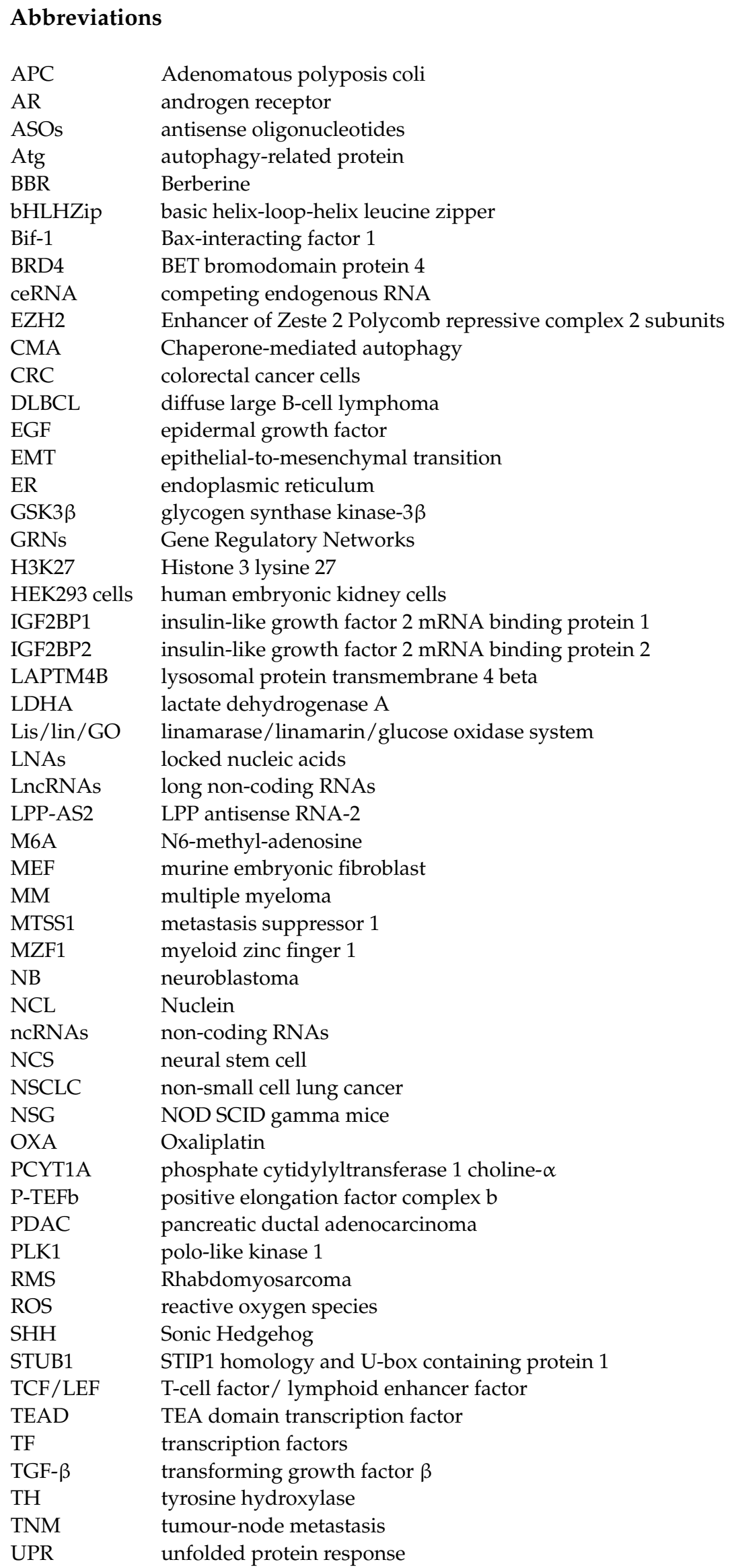




\section{References}

1. Malynn, B.A.; de Alboran, I.M.; O’Hagan, R.C.; Bronson, R.; Davidson, L.; DePinho, R.A.; Alt, F.W. N-myc can functionally replace c-myc in murine development, cellular growth, and differentiation. Genes Dev. 2000, 14, 1390-1399. [PubMed]

2. Kohl, N.E.; Kanda, N.; Schreck, R.R.; Bruns, G.; Latt, S.A.; Gilbert, F.; Alt, F.W. Transposition and amplification of oncogene-related sequences in human neuroblastomas. Cell 1983, 35, 359-367. [CrossRef]

3. Amati, B.; Littlewood, T.D.; Evan, G.I.; Land, H. The c-Myc protein induces cell cycle progression and apoptosis through dimerization with Max. EMBO J. 1993, 12, 5083-5087. [CrossRef]

4. Dang, C.V. MYC on the path to cancer. Cell 2012, 149, 22-35. [CrossRef] [PubMed]

5. Soucek, L.; Evan, G.I. The ups and downs of Myc biology. Curr. Opin. Genet. Dev. 2010, 20, 91-95. [CrossRef]

6. Kelly, K.; Cochran, B.H.; Stiles, C.D.; Leder, P. Cell-specific regulation of the c-myc gene by lymphocyte mitogens and plateletderived growth factor. Cell 1983, 35, 603-610. [CrossRef]

7. Satoh, K.; Yachida, S.; Sugimoto, M.; Oshima, M.; Nakagawa, T.; Akamoto, S.; Tabata, S.; Saitoh, K.; Kato, K.; Sato, S.; et al. Global metabolic reprogramming of colorectal cancer occurs at adenoma stage and is induced by MYC. Proc. Natl. Acad. Sci. USA 2017, 114, E7697-E7706. [CrossRef]

8. Adams, J.M.; Harris, A.W.; Pinkert, C.A.; Corcoran, L.M.; Alexander, W.S.; Cory, S.; Palmiter, R.D.; Brinster, R.L. The c-myc oncogene driven by immunoglobulin enhancers induces lymphoid malignancy in transgenic mice. Nature 1985, 318, 533-538. [CrossRef]

9. Stine, Z.E.; Walton, Z.E.; Altman, B.J.; Hsieh, A.L.; Dang, C.V. MYC, metabolism, and cancer. Cancer Discov. 2015, 5, 1024-1039. [CrossRef]

10. He, T.-C.; Sparks, A.B.; Rago, C.; Hermeking, H.; Zawel, L.; da Costa, L.T.; Morin, P.J.; Vogelstein, B.; Kinzler, K.W. Identification of c-MYC as a target of the APC pathway. Science 1998, 281, 1509-1512. [CrossRef]

11. Palomero, T.; Lim, W.K.; Odom, D.T.; Sulis, M.L.; Real, P.J.; Margolin, A.; Barnes, K.C.; O’Neil, J.; Neuberg, D.; Weng, A.P.; et al. NOTCH1 directly regulates c-MYC and activates a feed-forward-loop transcriptional network promoting leukemic cell growth. Proc. Natl. Acad. Sci. USA 2006, 103, 18261-18266. [CrossRef] [PubMed]

12. Swartling, F.J.; Savov, V.; Persson, A.I.; Chen, J.; Hackett, C.S.; Northcott, P.A.; Grimmer, M.R.; Lau, J.; Chesler, L.; Perry, A.; et al. Distinct neural stem cell populations give rise to disparate brain tumors in response to N-MYC. Cancer Cell 2012, 21, 601-613. [CrossRef]

13. Evan, G.I.; Littlewood, T.D. The role of c-myc in cell growth. Curr. Opin. Genet. Dev. 1993, 3, 44-49. [CrossRef]

14. Ayer, D.E.; Eisenman, R.N. A switch from Myc:Max to Mad:Max heterocomplexes accompanies monocyte/macrophage differentiation. Genes Dev. 1993, 7, 2110-2119. [CrossRef]

15. Laurenti, E.; Varnum-Finney, B.; Wilson, A.; Ferrero, I.; Blanco-Bose, W.E.; Ehninger, A.; Knoepfler, P.S.; Cheng, P.F.; MacDonald, H.R.; Eisenman, R.N.; et al. Hematopoietic stem cell function and survival depend on c-Myc and N-Myc activity. Cell Stem Cell 2008, 3, 611-624. [CrossRef] [PubMed]

16. Gandarillas, A.; Watt, F. c-Myc promotes differentiation of human epidermal stem cells. Genes Dev. 1997, 11, 2869-2882. [CrossRef]

17. Land, H.; Parada, L.F.; Weinberg, R.A. Tumorigenic conversion of primary embryo fibroblasts requires at least two cooperating oncogenes. Nature 1983, 304, 596-602. [CrossRef]

18. Mathew, P.; Valentine, M.B.; Bowman, L.C.; Rowe, S.T.; Nash, M.B.; Valentine, V.A.; Cohn, S.L.; Castleberry, R.P.; Brodeur, G.M.; Look, A.T. Detection of MYCN gene amplification in neuroblastoma by fluorescence in situ hybridization: A pediatric oncology group study. Neoplasia 2001, 3, 105-109. [CrossRef] [PubMed]

19. Davis, F.G.; McCarthy, B.J.; Freels, S.; Kupelian, V.; Bondy, M.L. The conditional probability of survival of patients with primary malignant brain tumors: Surveillance, epidemiology, and end results (SEER) data. Cancer 1999, 85, 485-491. [CrossRef]

20. Dang, C.V. MYC, metabolism, cell growth, and tumorigenesis. Cold Spring Harb. Perspect. Med. 2013, 3, a014217. [CrossRef]

21. Sodir, N.M.; Swigart, L.B.; Karnezis, A.N.; Hanahan, D.; Evan, G.I.; Soucek, L. Endogenous Myc maintains the tumor microenvironment. Genes Dev. 2011, 25, 907-916. [CrossRef] [PubMed]

22. Rapp, U.R.; Korn, C.; Ceteci, F.; Karreman, C.; Luetkenhaus, K.; Serafin, V.; Zanucco, E.; Castro, I.; Potapenko, T. MYC is a metastasis gene for non-small-cell lung cancer. PLoS ONE 2009, 4, e6029. [CrossRef]

23. Shchors, K.; Shchors, E.; Rostker, F.; Lawlor, E.R.; Brown-Swigart, L.; Evan, G.I. The Myc-dependent angiogenic switch in tumors is mediated by interleukin 1beta. Genes Dev. 2006, 20, 2527-2538. [CrossRef]

24. Berger, A.; Brady, N.J.; Bareja, R.; Robinson, B.; Conteduca, V.; Augello, M.A.; Puca, L.; Ahmed, A.; Dardenne, E.; Lu, X.; et al. N-Myc-mediated epigenetic reprogramming drives lineage plasticity in advanced prostate cancer. J. Clin. Invest. 2019, 129, 3924-3940. [CrossRef]

25. Murakami, S.; Nemazanyy, I.; White, S.M.; Chen, H.; Nguyen, C.D.K.; Graham, G.T.; Saur, D.; Pende, M.; Yi, C. A Yap-Myc-Sox2p53 Regulatory Network Dictates Metabolic Homeostasis and Differentiation in Kras-Driven Pancreatic Ductal Adenocarcinomas. Dev. Cell 2019, 51, 113-128.e9. [CrossRef]

26. Tao, R.; Murad, N.; Xu, Z.; Zhang, P.; Okonechnikov, K.; Kool, M.; Rivero-Hinojosa, S.; Lazarski, C.; Zheng, P.; Liu, Y.; et al. MYC Drives Group 3 Medulloblastoma through Transformation of Sox2+ Astrocyte Progenitor Cells. Cancer Res. 2019, 79, 1967-1980. [CrossRef] [PubMed]

27. Wang, Y.; Gao, S.; Wang, W.; Xia, Y.; Liang, J. Downregulation of N-Myc inhibits neuroblastoma cell growth via the Wnt/ $\beta$-catenin signaling pathway. Mol. Med. Rep. 2018, 18, 377-384. [CrossRef] [PubMed] 
28. Ooi, C.Y.; Carter, D.R.; Liu, B.; Mayoh, C.; Beckers, A.; Lalwani, A.; Nagy, Z.; De Brouwer, S.; Decaesteker, B.; Hung, T.T.; et al. Network Modeling of microRNA-mRNA Interactions in Neuroblastoma Tumorigenesis Identifies miR-204 as a Direct Inhibitor of MYCN. Cancer Res. 2018, 78, 3122-3134. [CrossRef]

29. Pandey, P.R.; Chatterjee, B.; Olanich, M.E.; Khan, J.; Miettinen, M.M.; Hewitt, S.M.; Barr, F.G. PAX3-FOXO1 is essential for tumour initiation and maintenance but not recurrence in a human myoblast model of rhabdomyosarcoma. J. Pathol. 2017, 241, 626-637. [CrossRef]

30. Kortlever, R.M.; Sodir, N.M.; Wilson, C.H.; Burkhart, D.L.; Pellegrinet, L.; Brown Swigart, L.; Littlewood, T.D.; Evan, G.I. Myc Cooperates with Ras by Programming Inflammation and Immune Suppression. Cell 2017, 171, 1301-1315.e14. [CrossRef] [PubMed]

31. Soucek, L.; Whitfield, J.; Martins, C.P.; Finch, A.J.; Murphy, D.J.; Sodir, N.M.; Karnezis, A.N.; Swigart, L.B.; Nasi, S.; Evan, G.I. Modelling Myc inhibition as a cancer therapy. Nature 2008, 455, 679-683. [CrossRef] [PubMed]

32. Ye, M.; Dong, S.; Hou, H.; Zhang, T.; Shen, M. Oncogenic Role of Long Noncoding RNAMALAT1 in Thyroid Cancer Progression through Regulation of the miR-204/IGF2BP2/m6A-MYC Signaling. Mol. Ther. Nucleic Acids 2020, 23, 1-12. [CrossRef]

33. Crea, F.; Venalainen, E.; Ci, X.; Cheng, H.; Pikor, L.; Parolia, A.; Xue, H.; Nur Saidy, N.R.; Lin, D.; Lam, W.; et al. The role of epigenetics and long noncoding RNA MIAT in neuroendocrine prostate cancer. Epigenomics 2016, 8, 721-731. [CrossRef]

34. Gargini, R.; García-Escudero, V.; Izquierdo, M.; Wandosell, F. Oncogene-mediated tumor transformation sensitizes cells to autophagy induction. Oncol. Rep. 2016, 35, 3689-3695. [CrossRef] [PubMed]

35. García-Escudero, V.; Gargini, R. Autophagy induction as an efficient strategy to eradicate tumors. Autophagy 2008, 4, 923-925. [CrossRef]

36. Gargini, R.; García-Escudero, V.; Izquierdo, M. Therapy mediated by mitophagy abrogates tumor progression. Autophagy 2011, 7, 466-476. [CrossRef] [PubMed]

37. Ying, H.; Kimmelman, A.C.; Lyssiotis, C.A.; Hua, S.; Chu, G.C.; Fletcher-Sananikone, E.; Locasale, J.W.; Son, J.; Zhang, H.; Coloff, J.L.; et al. Oncogenic Kras maintains pancreatic tumors through regulation of anabolic glucose metabolism. Cell 2012, 149, 656-670. [CrossRef]

38. Zhang, W.; Nandakumar, N.; Shi, Y.; Manzano, M.; Smith, A.; Graham, G.; Gupta, S.; Vietsch, E.E.; Laughlin, S.Z.; Wadhwa, M.; et al. Downstream of mutant KRAS, the transcription regulator YAP is essential for neoplastic progression to pancreatic ductal adenocarcinoma. Sci. Signal. 2014, 7, ra42. [CrossRef]

39. Brodeur, G.M. Neuroblastoma: Biological insights into a clinical enigma. Nat. Rev. Cancer 2003, 3, 203-216. [CrossRef] [PubMed]

40. Driman, D.; Thorner, P.S.; Greenberg, M.L.; Chilton-MacNeill, S.; Squire, J. MYCN gene amplification in rhabdomyosarcoma. Cancer 1994, 73, 2231-2237. [CrossRef]

41. Hachitanda, Y.; Toyoshima, S.; Akazawa, K.; Tsuneyoshi, M. N-myc gene amplification in rhabdomyosarcoma detected by fluorescence in situ hybridization: Its correlation with histologic features. Mod. Pathol. 1998, 11, $1222-1227$.

42. Williamson, D.; Lu, Y.J.; Gordon, T.; Sciot, R.; Kelsey, A.; Fisher, C.; Poremba, C.; Anderson, J.; Pritchard-Jones, K.; Shipley, J. Relationship between MYCN copy number and expression in rhabdomyosarcomas and correlation with adverse prognosis in the alveolar subtype. J. Clin. Oncol. 2005, 23, 880-888. [CrossRef]

43. He, J.; Li, F.; Zhou, Y.; Hou, X.; Liu, S.; Li, X.; Zhang, Y.; Jing, X.; Yang, L. LncRNA XLOC_006390 promotes pancreatic carcinogenesis and glutamate metabolism by stabilizing c-Myc. Cancer Lett. 2020, 469, 419-428. [CrossRef]

44. Xu, Z.; Liu, C.; Zhao, Q.; Lü, J.; Ding, X.; Luo, A.; He, J.; Wang, G.; Li, Y.; Cai, Z.; et al. Long non-coding RNA CCAT2 promotes oncogenesis in triple-negative breast cancer by regulating stemness of cancer cells. Pharmacol. Res. 2020, 152, 104628. [CrossRef] [PubMed]

45. Wu, J.; Zhu, P.; Lu, T.; Du, Y.; Wang, Y.; He, L.; Ye, B.; Liu, B.; Yang, L.; Wang, J.; et al. The long non-coding RNA LncHDAC2 drives the self-renewal of liver cancer stem cells via activation of Hedgehog signaling. J. Hepatol. 2019, 70, 918-929. [CrossRef]

46. Crea, F.; Clermont, P.L.; Parolia, A.; Wang, Y.; Helgason, C.D. The non-coding transcriptome as a dynamic regulator of cancer metastasis. Cancer Metastasis Rev. 2014, 33, 1-16. [CrossRef] [PubMed]

47. Sun, L.; Su, Y.; Liu, X.; Xu, M.; Chen, X.; Zhu, Y.; Guo, Z.; Bai, T.; Dong, L.; Wei, C.; et al. Serum and exosome long non coding RNAs as potential biomarkers for hepatocellular carcinoma. J. Cancer 2018, 9, 2631-2639. [CrossRef]

48. Conigliaro, A.; Costa, V.; Lo Dico, A.; Saieva, L.; Buccheri, S.; Dieli, F.; Manno, M.; Raccosta, S.; Mancone, C.; Tripodi, M.; et al. CD90+ liver cancer cells modulate endothelial cell phenotype through the release of exosomes containing H19 lncRNA. Mol. Cancer 2015, 14, 155. [CrossRef] [PubMed]

49. Roobol, M.J.; Schröder, F.H.; van Leeuwen, P.; Wolters, T.; van den Bergh, R.C.; van Leenders, G.J.; Hessels, D. Performance of the prostate cancer antigen 3 (PCA3) gene and prostate-specific antigen in prescreened men: Exploring the value of PCA3 for a first-line diagnostic test. Eur. Urol. 2010, 58, 475-481. [CrossRef] [PubMed]

50. Bellmunt, J.; Eigl, B.J.; Senkus, E.; Loriot, Y.; Twardowski, P.; Castellano, D.; Blais, N.; Sridhar, S.S.; Sternberg, C.N.; Retz, M.; et al Borealis-1: A randomized, first-line, placebo-controlled, phase II study evaluating apatorsen and chemotherapy for patients with advanced urothelial cancer. Ann. Oncol. 2017, 28, 2481-2488. [CrossRef] [PubMed]

51. Chi, K.N.; Higano, C.S.; Blumenstein, B.; Ferrero, J.M.; Reeves, J.; Feyerabend, S.; Gravis, G.; Merseburger, A.S.; Stenzl, A.; Bergman, A.M.; et al. Custirsen in combination with docetaxel and prednisone for patients with metastatic castration-resistant prostate cancer (SYNERGY trial): A phase 3, multicentre, open-label, randomised trial. Lancet Oncol. 2017, 18, 473-485. [CrossRef] 
52. Chery, J. RNA therapeutics: RNAi and antisense mechanisms and clinical applications. Postdoc J. 2016, 4, 35-50. [CrossRef] [PubMed]

53. Wang, W.T.; Han, C.; Sun, Y.M.; Chen, T.Q.; Chen, Y.Q. Noncoding RNAs in cancer therapy resistance and targeted drug development. J. Hematol. Oncol. 2019, 12, 55. [CrossRef]

54. Shen, X.; Corey, D.R. Chemistry, mechanism and clinical status of antisense oligonucleotides and duplex RNAs. Nucleic Acids Res. 2018, 46, 1584-1600. [CrossRef] [PubMed]

55. Sekhon, H.S.; London, C.A.; Sekhon, M.; Iversen, P.L.; Devi, G.R. c-MYC antisense phosphosphorodiamidate morpholino oligomer inhibits lung metastasis in a murine tumor model. Lung Cancer 2008, 60, 347-354. [CrossRef] [PubMed]

56. Iversen, P.L.; Arora, V.; Acker, A.J.; Mason, D.H.; Devi, G.R. Efficacy of antisense morpholino oligomer targeted to c-myc in prostate cancer xenograft murine model and a Phase I safety study in humans. Clin. Cancer Res. 2003, 9, 2510-2519. [PubMed]

57. Zhang, Z.; Lin, W.; Lin, Y.; Kang, M.; Zhu, J.; Tong, Z.; Wu, L.; Sun, J.; Lin, J. Long intergenic non-coding RNA Linc00485 promotes lung cancer progression by modulating miR-298/c-Myc axis. J. Cell Mol. Med. 2021, 25, 309-322. [CrossRef]

58. Liu, S.; Zheng, Y.; Zhang, Y.; Zhang, J.; Xie, F.; Guo, S.; Gu, J.; Yang, J.; Zheng, P.; Lai, J.; et al. Methylation-mediated LINC00261 suppresses pancreatic cancer progression by epigenetically inhibiting c-Myc transcription. Theranostics 2020, 10, 10634-10651. [CrossRef] [PubMed]

59. Zhang, X.; Niu, W.; Mu, M.; Hu, S.; Niu, C. Long non-coding RNA LPP-AS2 promotes glioma tumorigenesis via miR-75p/EGFR/PI3K/AKT/c-MYC feedback loop. J. Exp. Clin. Cancer Res. 2020, 39, 196. [CrossRef] [PubMed]

60. Li, H.; Liu, J.; Cao, W.; Xiao, X.; Liang, L.; Liu-Smith, F.; Wang, W.; Liu, H.; Zhou, P.; Ouyang, R.; et al. C-myc/miR-150/EPG5 axis mediated dysfunction of autophagy promotes development of non-small cell lung cancer. Theranostics 2019, 9, 5134-5148. [CrossRef] [PubMed]

61. Cianfanelli, V.; Fuoco, C.; Lorente, M.; Salazar, M.; Quondamatteo, F.; Gherardini, P.F.; De Zio, D.; Nazio, F.; Antonioli, M.; D'Orazio, M.; et al. AMBRA1 links autophagy to cell proliferation and tumorigenesis by promoting c-Myc dephosphorylation and degradation. Nat. Cell Biol. 2015, 17, 20-30. [CrossRef] [PubMed]

62. Hart, L.S.; Cunningham, J.T.; Datta, T.; Dey, S.; Tameire, F.; Lehman, S.L.; Qiu, B.; Zhang, H.; Cerniglia, G.; Bi, M.; et al. ER stress-mediated autophagy promotes Myc-dependent transformation and tumor growth. J. Clin. Invest. 2012, 122, 4621-4634. [CrossRef] [PubMed]

63. Gomes, L.R.; Menck, C.F.M.; Cuervo, A.M. Chaperone-mediated autophagy prevents cellular transformation by regulating MYC proteasomal degradation. Autophagy 2017, 13, 928-940. [CrossRef] [PubMed]

64. Zhai, S.; Xu, Z.; Xie, J.; Zhang, J.; Wang, X.; Peng, C.; Li, H.; Chen, H.; Shen, B.; Deng, X. Epigenetic silencing of LncRNA LINC00261 promotes c-myc-mediated aerobic glycolysis by regulating miR-222-3p/HIPK2/ERK axis and sequestering IGF2BP1. Oncogene 2021, 40, 277-291. [CrossRef]

65. Shigeyasu, K.; Toden, S.; Ozawa, T.; Matsuyama, T.; Nagasaka, T.; Ishikawa, T.; Sahoo, D.; Ghosh, P.; Uetake, H.; Fujiwara, T. The PVT1 lncRNA is a novel epigenetic enhancer of MYC, and a promising risk-stratification biomarker in colorectal cancer. Mol. Cancer 2020, 19, 155. [CrossRef]

66. Olivero, C.E.; Martínez-Terroba, E.; Zimmer, J.; Liao, C.; Tesfaye, E.; Hooshdaran, N.; Schofield, J.A.; Bendor, J.; Fang, D.; Simon, M.D.; et al. p53 Activates the Long Noncoding RNA Pvt1b to Inhibit Myc and Suppress Tumorigenesis. Mol. Cell 2020, 77, 761-774.e8. [CrossRef]

67. Hu, Y.; Wang, F.; Xu, F.; Fang, K.; Fang, Z.; Shuai, X.; Cai, K.; Chen, J.; Hu, P.; Chen, D.; et al. A reciprocal feedback of Myc and lncRNA MTSS1-AS contributes to extracellular acidity-promoted metastasis of pancreatic cancer. Theranostics 2020, 10, 10120-10140. [CrossRef]

68. Usman, R.M.; Razzaq, F.; Akbar, A.; Farooqui, A.A.; Iftikhar, A.; Latif, A.; Hassan, H.; Zhao, J.; Carew, J.S.; Nawrocki, S.T.; et al. Role and mechanism of autophagy-regulating factors in tumorigenesis and drug resistance. Asia. Pac. J. Clin. Oncol. 2021, 17, 193-208. [CrossRef] [PubMed]

69. Toh, P.P.C.; Luo, S.; Menzies, F.M.; Raskó, T.; Wanker, E.E.; Rubinsztein, D.C. Myc inhibition impairs autophagosome formation. Hum. Mol. Genet. 2013, 22, 5237-5248. [CrossRef]

70. Sears, R.C. The Life Cycle of C-Myc: From Synthesis to Degradation. Cell Cycle 2004, 3, 1131-1135. [CrossRef]

71. Mo, H.; He, J.; Yuan, Z.; Wu, Z.; Liu, B.; Lin, X.; Guan, J. PLK1 contributes to autophagy by regulating MYC stabilization in osteosarcoma cells. Onco Targets Ther. 2019, 12, 7527-7536. [CrossRef] [PubMed]

72. Kon, M.; Kiffin, R.; Koga, H.; Chapochnick, J.; Macian, F.; Varticovski, L.; Cuervo, A.M. Chaperone-mediated autophagy is required for tumor growth. Sci. Transl. Med. 2011, 3, 109ra117. [CrossRef]

73. Vara-Perez, M.; Felipe-Abrio, B.; Agostinis, P. Mitophagy in Cancer: A Tale of Adaptation. Cells 2019, 8, 493. [CrossRef] [PubMed]

74. Zhang, C.; Nie, P.; Zhou, C.; Hu, Y.; Duan, S.; Gu, M.; Jiang, D.; Wang, Y.; Deng, Z.; Chen, J.; et al. Oxidative stress-induced mitophagy is suppressed by the miR-106b-93-25 cluster in a protective manner. Cell Death Dis. 2021, 12, 209. [CrossRef] [PubMed]

75. Kim, E.H.; Choi, K.S. A critical role of superoxide anion in selenite-induced mitophagic cell death. Autophagy 2008, 4, 76-78. [CrossRef] [PubMed]

76. Takahashi, Y.; Hori, T.; Cooper, T.K.; Liao, J.; Desai, N.; Serfass, J.M.; Young, M.M.; Park, S.; Izu, Y.; Wang, H.-G. Bif-1 haploinsufficiency promotes chromosomal instability and accelerates Myc-driven lymphomagenesis via suppression of mitophagy. Blood 2013, 121, 1622-1632. [CrossRef] 
77. Pelengaris, S.; Littlewood, T.; Khan, M.; Elia, G.; Evan, G. Reversible activation of c-Myc in skin: Induction of a complex neoplastic phenotype by a single oncogenic lesion. Mol. Cell 1999, 3, 565-577. [CrossRef]

78. Bisgrove, D.A.; Mahmoudi, T.; Henklein, P.; Verdin, E. Conserved P-TEFb-interacting domain of BRD4 inhibits HIV transcription. Proc. Natl. Acad. Sci. USA 2007, 104, 13690-13695. [CrossRef]

79. Delmore, J.E.; Issa, G.C.; Lemieux, M.E.; Rahl, P.B.; Shi, J.; Jacobs, H.M.; Kastritis, E.; Gilpatrick, T.; Paranal, R.M.; Qi, J.; et al. BET Bromodomain Inhibition as a Therapeutic Strategy to Target c-Myc. Cell 2011, 146, 904-917. [CrossRef] [PubMed]

80. Wu, R.; Li, L.; Bai, Y.; Yu, B.; Xie, C.; Wu, H.; Zhang, Y.; Huang, L.; Yan, Y.; Li, X.; et al. The long noncoding RNA LUCAT1 promotes colorectal cancer cell proliferation by antagonizing Nucleolin to regulate MYC expression. Cell Death Dis. 2020, 11, 908. [CrossRef]

81. Chen, Q.; Shen, H.; Zhu, X.; Liu, Y.; Yang, H.; Chen, H.; Xiong, S.; Chi, H.; Xu, W. A nuclear lncRNA Linc00839 as a Myc target to promote breast cancer chemoresistance via PI3K/AKT signaling pathway. Cancer Sci. 2020, 111, 3279-3291. [CrossRef] [PubMed]

82. Sun, W.; Li, J.; Zhou, L.; Han, J.; Liu, R.; Zhang, H.; Ning, T.; Gao, Z.; Liu, B.; Chen, X.; et al. The c-Myc/miR-27b-3p/ATG10 regulatory axis regulates chemoresistance in colorectal cancer. Theranostics 2020, 10, 1981-1996. [CrossRef] [PubMed]

83. Meng, Y.; Wang, L.; Chen, D.; Chang, Y.; Zhang, M.; Xu, J.-J.; Zhou, R.; Zhang, Q.-Y. LAPTM4B: An oncogene in various solid tumors and its functions. Oncogene 2016, 35, 6359-6365. [CrossRef]

84. Li, L.; Wei, X.H.; Pan, Y.P.; Li, H.C.; Yang, H.; He, Q.H.; Pang, Y.; Shan, Y.; Xiong, F.X.; Shao, G.Z.; et al. LAPTM4B: A novel cancer-associated gene motivates multidrug resistance through efflux and activating PI3K/AKT signaling. Oncogene 2010, 29, 5785-5795. [CrossRef]

85. Xiong, J.; Wang, L.; Fei, X.-C.; Jiang, X.-F.; Zheng, Z.; Zhao, Y.; Wang, C.-F.; Li, B.; Chen, S.-J.; Janin, A.; et al. MYC is a positive regulator of choline metabolism and impedes mitophagy-dependent necroptosis in diffuse large B-cell lymphoma. Blood Cancer J. 2017, 7, e582. [CrossRef] [PubMed] 